\title{
Quantifying and reporting greenhouse gas emissions at local level
}

\author{
Izabela Sówka $^{1, *}$, and Yaroslav Bezyk ${ }^{1}$ \\ ${ }^{1}$ Unit of Ecologistics and Environmental Risk Management, Faculty of Environmental Engineering, \\ Wroclaw University of Science and Technology, Wyb. Wyspiańskiego 27 St., 50-370, Wroclaw, \\ Poland
}

\begin{abstract}
Cities as global centers of consumption and production often are a significant and growing source of greenhouse gas (GHG) emissions. At the same time, local authorities are increasingly taking action on climate change by focusing on reducing GHG emissions and efficiency improvement opportunities. To assess and reduce the overall greenhouse gas emission level from an urban area, it is necessary to identify all the activities and processes which generate these emissions. GHG inventory gives an opportunity to get wider knowledge for city's community about spatial emission processes and emissions contribution of key sources categories at the local scale. Inventory is being used for decision-making purposes and strategic planning in emission reduction policy. The goal of this paper was to clarify the major methodological challenges of GHG monitoring at the urban level. The paper is based on the discussion of different methods and approaches to assessing GHG emissions at the local level. It is presented sectoral GHGs emission trends in selected urban areas and compared $\mathrm{CO}_{2}$ emission level in different countries and metropolises and variable European cities guidance. The study determines the inventory tools of GHGs emission taking into account the characteristics of main sources at local levels.
\end{abstract}

\section{Introduction}

Strong ability to take effective action on climate mitigation and adaptation strategies, monitoring and verifying progress in GHGs reduction depends on reliable GHG emission inventory. Under the United Nations Framework Convention on Climate Change, the GHG inventory is reporting emissions and sinks of anthropogenic greenhouse gases within a region and period [1]. Based on the Kyoto Protocol classification system, the most important direct greenhouse gases emitted by humans include carbon dioxide $\left(\mathrm{CO}_{2}\right)$, methane $\left(\mathrm{CH}_{4}\right)$, nitrous oxide $\left(\mathrm{N}_{2} \mathrm{O}\right)$, and several fluorine-containing halogenated substances (hydrofluorocarbons, perfluorocarbons and sulfur hexafluoride) [2].

The internationally-accepted methods used to calculate GHG emissions and sinks are provided by Intergovernmental Panel on Climate Change (IPCC). Applying defined by the IPCC guidelines uses standardized field data from commonly determined processes in sectoral categories (energy, industrial processes and product use, agriculture, waste

* Corresponding author: izabela.sowka@pwr.edu.pl 
management) [3], but not detailed enough for local inventory system of different countries and regions to show the overall carbon footprint of city activities. The newest 21 st yearly session of the Conference of the Parties (COP) to the UNFCCC 1992, was held in Paris from 30 November to 12 December 2015, proclaimed the important role of city's level actions in the field of climate change [4].

The GHG emissions reporting at the local scale is a precondition for creating a city's mitigation mechanisms and removal of GHGs [5]. Recently, in practice of developing the methodological framework for calculating urban GHGs emission were involved local authorities from different countries. As a result, a network of local initiatives such as ICLEI - Local Governments for Sustainability, C40 Cities Climate Leadership Group, the Covenant of Mayors is represented in international climate negotiations.

The comparability of inventory data between different cities is limited due to varying methodological approaches and frequency of reporting process. Since regions and countries have contrasting economic and social structures, $\mathrm{CO}_{2}$ emissions can be expressed in $\mathrm{CO}_{2}$-eq emissions by Gross Domestic Product $\left(\mathrm{CO}_{2}\right.$-eq /GDP) and per capita $\left(\mathrm{CO}_{2}\right.$-eq /cap). These indicators show the relationship between the size of city's population and the amount of GHGs emitted and improvements in the emissions associated with energy generation [6]. The $\mathrm{CO}_{2}$-eq/GDP and $\mathrm{CO}_{2}$-eq/capita measurement help to investigate the relationship between the structure of the economy, the composition of local community and emissions and used as a benchmark for making an allocation of emission sources.

\section{Variability of $\mathrm{CO}_{2}$ emissions in European cities}

The numeric per capita GHG emission values are represented at the city-scale while incorporating the scope of related emissions versus the larger national scale emission levels (Fig. 1). In general, wealthier countries as well as cities having higher emissions per capita, due to higher rates of consumption and more energy-intensive lifestyles, likewise urbanization brings higher energy usage, although other factors such as population density and geography also have an influence [7].

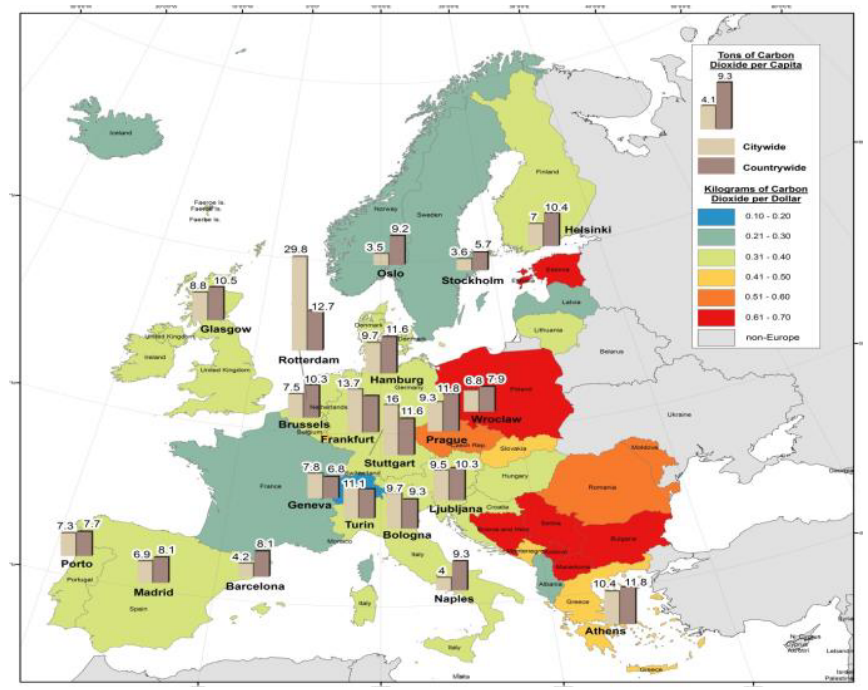

Fig. 1. Europe-wide $\mathrm{CO}_{2}$ emissions per capita and unit of GDP in 2005. Source: Base map source: OpenStreetMap.

The created map below on the data from the Word Bank [7] shows the European countrywide and citywide $\mathrm{CO}_{2}$ emissions per capita (tons of $\mathrm{CO}_{2}$-eq per person) and per 
Gross Domestic Product ( $\mathrm{kg} \mathrm{CO}_{2}$ per PPP \$1 GDP). The expressed greenhouse gas emission per GDP from selected countries represents how green are the different European economies. Poland's per capita emissions with $7.9 \mathrm{CO}_{2}$-eq per person, relative values to 2005, are similar to the European Union (EU) average too, but at the same time the amount of GHGs emitted per GDP in Poland are much higher $-0.6 \mathrm{~kg} \mathrm{CO}_{2}$ per PPP \$1 GDP. The main reason of this is lower income level and less emissions-efficient of the Polish economy.

Given the emission level in Poland and the share of fossil fuels in energy sector, the critical difference of Poland's energy production and emissions structure from EU in 2005 was due to the dominance of coal and lignite (above 90\%) in total energy production [7]. To summarize, the reflection of GHG emissions from city's and national level is not only in absolute form but in the manner of per inhabitant, which helps to develop a more holistic GHG emissions footprint that shows the overall impact of a city's activities on local and national GHG emissions reduction targets.

\section{Approaches to GHG accounting and analysis of existing methodologies}

\subsection{GHG inventory tools used at the local level}

Main approaches that can be applied for estimating GHG emissions are emission factors (quantifying the emissions per activity); continuous emissions monitoring (accurate and real-time data); source testing (periodic sampling and analysis of emitted species); material balance (Input $=$ Output + Emissions). In the range of gases and GHG emission sources, the emission factors method and mass balance method are commonly used for the inventory process [8].

Emission factors specific to the urban area are often based on the recommended by Intergovernmental Panel on Climate Change (IPCC) for country-level "tiered" (referred Tier 1, 2, 3 data source) measuring rules [3]. The tier 1 approach reflects default activity data, e.g. readily available energy statistics, production statistics and corresponding emission factors for typical/familiar process conditions. Tier 2 approach is more specific to regions, which includes country-specific information on process conditions and technological details. Tier 3 approach is the most detailed method and can use facility level data, including sophisticated models [3].

The concept of 'scope' allocations with regards to GHG emissions for communities allows accounting for direct and indirect emissions. Three "scopes" categories depending on where they physically occur (within and without city boundaries) are defined in the GHG Protocol standard for cities known as 'Global Protocol for Community-Scale Greenhouse Gas Emission Inventories' (GPC) [9]. The GPC Protocol was created in cooperation with World Resources Institute, C40 Cities Climate Leadership Group and Local Governments for Sustainability (ICLEI) [9].

The several of programs for improving the process of quantification of greenhouse gases are designed by ICLEI. The major of them are: Clean Air and Climate Protection (CACP) Software a management tool for accounting emission, associated with energy and power consumption, fuel use, and waste disposal [10]; Harmonized Emissions Analysis Tool (HEAT +) supporting program for creating GHG inventory and cost-effective impact on emissions reductions from energy consumption, transport and waste sources [11].

In 2008 was established the Covenant of Mayors (CoM) $\neg$ the largest cities initiative for combating climate change. The CoM association has taken commitments regarding the EU $\mathrm{CO}_{2}$ reduction objectives by more than $20 \%$ by 2020 compared to 1990 [12]. For the 
reduction targets, the participated cities have to provide the Baseline Emission Inventory (BEI) quantifies the amount of $\mathrm{CO}_{2}$ emitted due to energy consumption in their territory through the implementation of Sustainable Energy Action Plans [13].

The Greenhouse Gas Regional Inventory Process (GRIP) for city-scale emissions accounting was developed by the University of Manchester. The GRIP Programme is based on three calculations methods: level 1, level 2 and level 3, similar to the IPCC's tiered approaches. Level 1 is associated with the high standard of accuracy; level 2 includes individually collected or cumulative dataset with average accuracy records; level 3 is determined as a category with the highest level of uncertainty [14].

As follows from the above, the inventory tools and methodologies furthermore differ with how cities allocate emissions to the territory where they were emitted. For instance, in city's emissions accounting and reporting practices it should be clearly distinguished whether only the direct (sources located in cities) and/or also indirect (upstream) emissions are calculated (clear measurement frameworks), what can have major consequences for the outcome of the inventory process.

\subsection{Measurement boundaries, scopes and sources of GHG emission}

Depending on the level of approach in estimating GHG emissions, there is top-down approach (used in national GHG inventories) and bottom-up approach (applied at the regional or municipal level). Data collection and processing in bottom-up approach guarantees a relatively accurate inventory at the local level, but accounting procedures can have varieties from site to site. Data aggregating and scaling in top-down approach reflects the national average statistics for an emission source but due to the little interaction between different levels not accurately reflect local conditions of emissions [15]. Finally, local level inventories are often based on a mix of bottom-up and top-down approach.

The area where emissions are measured relates to the boundaries of the measurement. It includes different aspects such as activity data (data on the fuel consumption or the relevant electricity/heat production in or outside the territory); scaling data principle (GHG are allocated within the geographic boundaries of a city or out-of-boundary); allocation of emission loads on the respective sources and consumption sectors (allocation methods and references for emissions related to energy sources used to production electricity and heat).

Electricity using activities carried out by cities are the cause of GHG emissions elsewhere, which are taken into account when allocating $\mathrm{CO}_{2}$ emissions and fossil fuel used to electricity/heat produced. An allocation - is the distribution of emissions to the main product and co-products [16]. The allocation mechanism of $\mathrm{CO}_{2}$ emission allowances differs significantly depending on: the variety of method used; the efficiencies of dedicated electricity/heat plants; thermodynamic medium temperature; other reference efficiencies assumed; energy policy reasons in the country (different taxation to CHP) [17]. There are two widely used categories of allocation methods $[18,19]$ :

Thermodynamic Allocation Methods based on:

- Energy content of heat and electricity: emissions are allocated to the produced heat and electricity is based on the primary energy content of the produced products;

- Exergy content of heat and electricity as the main product (exergy - energy that is available to be used) covers the main part of the $\mathrm{CO}_{2}$ emissions, and the heat is the by-product (anergy - the balance from converted the energy, unavailable part).

Economic Allocation Methods based on:

- The Benefit Distribution Method: all emissions are allocating to heat production;

- Alterative Power Method: electricity covers all emissions of CHP production;

- The equal mix of both energy and heat side: total emissions is allocated to fixed sharing $50 \%-50 \%$ between power and heat products. 
To provide accuracy and to improve transparency of GHG inventory process, it is necessary to identify scope and sources of GHG emissions. Based on the latest tools of ICLEI, the GPC Protocol is counting the direct and indirect emissions, grouped it into three boundaries (scopes 1, 2, 3) [9]. Scope 1 including all direct GHG emissions within the city geographic boundary; Scope 2 including all indirect emissions occurred inside or and outside local authority (consumption of electricity, heat or steam); Scope 3 estimates all other indirect emissions that occur outside local authority (electricity transportation related activities, waste generation) [9]. The major sources of GHG emissions from city activities covered by GPC Protocol are following: stationary energy; transportation, industrial processes and product use, waste, agriculture, forestry, and other land use (AFOLU), other indirect emissions and sources of fugitive emissions [9].

Attributing anthropogenic carbon concentrations to a specific source is challenging because emissions vary depending on type and location, technology type and operational practices, meteorological conditions, time framework, etc. [20]. Then, the exact amount of emitted GHG emissions from selected sources at urban area can be hard to determine, and some sources are better known than others. With pure data of actual field emission measurements, individual inventories can use data for a specific sector from national statistics if the relevant data are difficult to obtain at the local level and could be scaled. The rule is that scaling data from national GHG inventories can be applicable within local authority if data for a selected sector are broken down from the national GHG inventory and sector share is not considerable in overall emissions from the city [21].

\subsection{Structure of GHG emission inventory process}

The process of preparing the GHG inventory includes following stages: identifying geospatial features of territory on inventory, clarification of sources and terms of GHG emissions, selection of an emissions quantification methodology, determination emission factors for the data collected, evaluating uncertainties, verification and improvement inventory, interpretation and communicating of inventory results, performing a life-cycle inventory and monitoring of future greenhouse gas emissions [22]. The overall architecture of the accounting procedure is based on the value chain concept: the primary activities data are transformed in the form of a value-added model of future GHG emissions scenarios (Fig. 2).

Within the territorial framework identification is required detailed knowledge about the area of emission inventory and/or about geospatial features; identifying key categories and term of conditions for the emergence and fate of greenhouse gas emissions [23]. In the next step, it is important to separate existing assessment approaches and methodologies and planning possibilities of implementation in local conditions and/or identified sources. The step of selecting methods is provided due to the realization of the two important tasks: first - analysis of inventory scope and city-induced frameworks and checking impacts of selected level of detail on the final result of GHG inventory.

During second objective it should be planned the core features of adaptation of chosen inventory methods to the local level. Using this option, municipal administrators can choose for evaluation either the direct impact of GHG emissions from a different economy and the residential sectors within the city operational boundary and/or indirect and embodied GHG emissions, which occur inside or outside urban geographical/ political boundary. The calculation beyond selection of the detail standards and allocation of emissions also required the determination of the corresponding territory-specific emission factors [24]

In a process for quantifying GHG emissions one of the most important parts is a clear estimation of the level of uncertainties during information processing and verification for 
inventory data. The consideration of the possibility to use developed GHG inventory materials (data sources, inventory plan, the scale of the inventory, calculation tools, presenting results) and specific emission factors for selected activity data should be provided by monitoring, reporting, and verification (MRV) process at regular time intervals [25].

Monitoring covers the scientific part of MRV process (accuracy and precision of the estimates); by reporting is provided data harmonizing (better access to information and high level of transparency); verification is an assessment of the completeness and accuracy of the collected database [26] In this step, to monitor the emission loads of different production and consuming sectors in terms of improving inventory system and GHG reduction strategy the Life Cycle Assessment (LCA) method could be applied. A reliable life-cycle inventory (LCI) performance as a value-added methodological structure is crucial to achieving inventory goals [27].

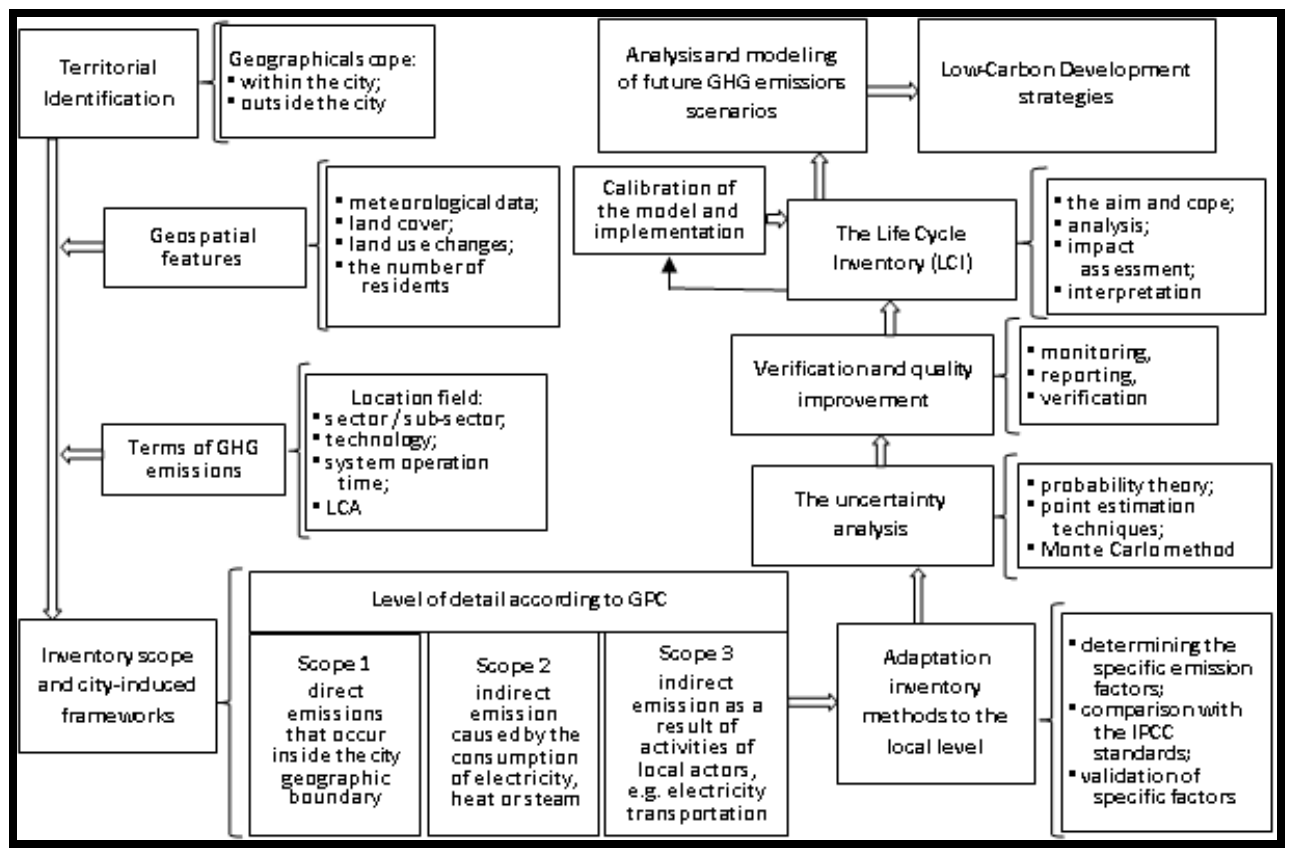

Fig. 2. Schematic overview of the GHG emission inventory process for the city area (Source:

Author's construct).

The following step is the interpretation of the GHG inventory results. The identified emissions trends in research area are used to impact on activities where emissions occur. The aim is to reduce given GHGs amount, improve energy efficiency and implement innovative sectoral and cross-sectoral low carbon initiatives. Further to predict future change in GHGs, it could be prepared geostatistical forecasting model of the spatial distribution of greenhouse gas emissions that helps to estimate risks (health, environmental, etc.) associated with a wide variety of global warming emissions, as well as to manage emissions reduction efforts and allocate resources.

\section{Conclusions}

Cities play a dominant role in global consumption and production. They are associated with serious problems like air pollution, greenhouse gas emissions, waste, and poverty. But urban areas also offer opportunities for sustainable development. The world's municipalities 
experience shows that the building process of GHG emissions quantification and reporting could enable cities to set realistic reduction targets and manage their mitigation and adaptation efforts. The local inventory data gives an opportunity to get wider knowledge about spatial emission processes in the sectors of the economy not only at the national level but also at the level of administrative units.

Accordingly, the first stage of this research was devoted to studying GHG emission accounting and inventory techniques at national and local level. The study has shown that many initiatives on the GHG inventories at a local level are being applied in different European countries and worldwide. Some of the most advanced GHG accounting tools are analyzed, and the most important differences between these tools are highlighted.

Finally, it was shown that there are existing meaningful differences across the respective accounting tools and inventories of compared cities in Europe. Depending on the purpose of the GHG calculation different methods may be used. For instance, the choice whether only direct or also indirect emissions are taken into account (scope of the measurement), analytical framework and approaches to allocating emissions allowances have major consequences for the outcome of the inventory process. Territorial framework and timing variability, nature of future data releases have also influence on progress towards updating emission factors and identifying activity data across all sectors.

The investigations were co-financed within the framework of the project No. 0402/0077/16 with the specific subsidy granted for the Faculty of Environmental Engineering Wroclaw University of Science and Technology (W-7) by the Minister of Science and Higher Education to conduct research and development work and related tasks contributing to the development of young scientists and doctoral students in 2016/2017.

\section{References}

1. UNFCCC: United Nations Framework Convention on Climate Change. United Nations, FCCC/INFORMAL/84 GE.05-62220 (E) 200705, Secretariat of the United Nations Framework Convention on Climate Change, Bonn, Germany, 15 pp., (1992).

2. J. Depledge, United Nations Framework Convention on Climate Change (UNFCCC) Technical paper: Tracing the Origins of the Kyoto Protocol: An Article-by-Article Textual History (PDF), UNFCCC, (2000).

3. J.T. Houghton, L.G. Meira Filho, B.A. Callander, N. Harris, A. Kattenberg, and K. Maskell (eds.). IPCC (1996) Climate Change (1995): The Science of Climate Change. Intergovernmental Panel on Climate Change. Cambridge University Press. Cambridge, United Kingdom.

4. World Resources Institute. Aniruddha Dasgupta. COP21 Highlights Importance of City Actions in the Climate Fight, (2015). Available at http://www.wri.org/blog/2015/12/cop21-highlights-importance-city-actions-climatefight

5. M. Sippel, Cities in Germany and their climate commitments: More hype than substance? Discussion Paper. University of Stuttgart. IER - Institute of Energy Economics and Rational Energy Use. June (2010).

6. B. Dawson, M. Spannagle. The complete guide to climate change, Routledge, Oxon, United Kingdom, (2009).

7. WRI (World Resources Institute)/World Bank. World Resources: The Wealth of the Poor - Managing Ecosystems to Fight Poverty. Washington, DC: WRI, (2005).

8. K. Ritter, M. Lev-On, and T. Shires. Understanding Uncertainty in Greenhouse Gas Emission Estimates: Technical Considerations and Statistical Calculation Methods." 
American Petroleum Institute, Washington DC, Background paper for EPA 19th International Emissions Inventory Conference, San Antonio, Texas, (2010).

9. The Global Protocol for Community-Scale Greenhouse Gas Emission Inventories (GPC). An Accounting and Reporting Standard for Cities. November (2014).

10. International Council for Local Environmental Initiatives (ICLEI) - Clean Air and Climate Protection (CACP) Software. Available at http://en.openei.org/wiki/International_Council_for_Local_Environmental_Initiatives (ICLEI) Clean_Air_and_Climate_Protection_Software Tools

11. International Council for Local Environmental Initiatives (ICLEI) - HEATplus Harmonized Emissions Analysis Tool. Available at http://heat.iclei.org/heatplusgpc/indexnew.aspx

12. Covenant of Mayors for Climate \& Energy, (2016). Available from: http://www.covenantofmayors.eu/The-Covenant-of-Mayors-for-Climate.html

13. How to develop a sustainable energy action plan (SEAP) - guidebook, Luxembourg: Publications Office of the European Union, (2010).

14. S. Carney, S. Shackley. The greenhouse gas regional inventory project (GRIP): Designing and employing a regional greenhouse gas measurement tool for stakeholder use. Energy Policy 37, (2009).

15. C. Nick Hewitt (Editor), Andrea V. Jackson (Editor). Handbook of Atmospheric Science: Principles and Applications. ISBN: 978-0-632-05286-8. 648 pages, (2009).

16. The impact of modified EU ETS allocation principles on the economics of CHP-Based district heating networks. Günther Westner and Reinhard Madlener. FCN Working Paper No. 4/2011, (2011).

17. WBCSD/WRI. Allocation of Emissions from a Combined Heat and Power (CHP) Plant - Excel tool. (2006). Available at http://www.ghgprotocol.org/calculation-tools/

18. M. Harmelink, Assessment of $\mathrm{CO}_{2}$ emissions of electricity and heat used at industrial plants. Harmelink Consulting, The Netherlands Lex Bosselaar, (2014).

19. Arto Nuorkivi. Allocation of Fuel Energy and Emissions to Heat and Power in CHP. Energy-AN Consulting. FINAL REPORT. Sep 7, (2010).

20. U. S. Environmental Protection Agency. Office of Policy, Planning, and Evaluation. Inventory of U.S. Greenhouse gas emissions and sinks, 1990-1994. EPA 230-R-96006. Washington, DC, November, (1995).

21. N. Bader, R. Bleischwitz, Measuring Urban Greenhouse Gas Emissions: The Challenge of Comparability. Cities and Climate Change, (2009).

22. B. Vigon, D. Tolle, B. Cornaby, H. Latham, I. Batte. Life-cycle assessment inventory guidelines and principles. Columbus, (1993).

23. German Informative Inventory Report. Chapter 2.6 - QA/QC and Verification Methods. Updates, (2016). Available at http://iir-de.wikidot.com/qa-qc-andverification-methods

24. American Association of State Highway and Transportation Officials (AASHTO). Greenhouse gas emission inventory methodologies for state transportation departments, (2011).

25. J. Wintergreen, T. Delaney, ISO 14064, International Standard for GHG Emissions Inventories and Verification. Available at https://www3.epa.gov/ttnchie1/conference/ei16/session13/wintergreen.pdf

26. V. Bellassen, N. Stephan, M. Afriat, E. Alberola, A. Barker, J. Chang, P. Chiquet, C. Cochran, I. Deheza, M. Dimopoulos, C. Foucherot, C. Jacquier, G. Morel, R. Robinson, R. Shishlov. Monitoring, Reporting and verifying emissions in the climate economy. Nature Climate Change, (2015), 5, (4), 319-328.

27. B.V. Babu, Life Cycle Inventory Analysis. International Conference on Life cycle assessment \& Life cycle management methodologies. Malaysia. December 4-5, (2006). 